\title{
Neisseria Gonorrhoeae Bacteraemia: An Antipodean Case Study
}

\section{Jayachandran Nair*}

Kalgoorlie Regional Hospital, Western Australia, Australia

*Corresponding author: Jayachandran Nair, Path West Laboratory Medicine WA, Kalgoorlie Regional Hospital, Piccadilly Street, Kalgoorlie 6430, Western Australia, Australia, Tel: +61458288469; E-mail: jayachandran.nair@health.wa.gov.au

Received date: Mar 26, 2014; Accepted date: May 21, 2014; Published date: May 28, 2014

Copyright: @ 2014 Nair J. This is an open-access article distributed under the terms of the Creative Commons Attribution License, which permits unrestricted use, distribution, and reproduction in any medium, provided the original author and source are credited.

\begin{abstract}
The objective of this case study was to highlight the role played by our regional laboratory in identifying $N$. gonorrhoeae bacteraemia infection in an otherwise un-suspecting patient who presented to Emergency department with fever. Using blood culture technique with BACTEC 9240, plate culture, catalase test, oxidase test and Gram's stain, preliminary diagnosis was made at the regional laboratory. Blood culture became positive on day 3 and Gram's stain from culture day 4 identified intracellular Gram-negative diplococci. The blood picture showed neutrophilia and a raised CRP indicating an underlying bacterial infection. This helped the physicians in starting prompt treatment with Ceftriaxone $500 \mathrm{mg}$ and Azithromycin $1 \mathrm{~g}$. The culture plates and blood culture bottles were then sent to the referral laboratory where confirmatory diagnosis was made using MALDI TOF (Matrix Assisted Laser Desorption Ionisation- Time of Flight), that gave a reading of 2.2 and a VITEK 2 system that gave a $99 \%$ probability. The timely detection of Neisseria by the regional laboratory helped the local health authorities to isolate the patient and treat him promptly, thereby preventing the spread of this infection to other parts of his body.
\end{abstract}

Keywords: Neisseria gonorrhoeae; Bacteraemia; MALDI-TOF; VITEK-2

\section{Introduction}

Neisseria gonorrhoea causes well known sexually transmitted disease such as genital, pharyngeal and ano-rectal infections. Blood stream invasions occur only in $0.5-3 \%$ of the infections and result in disseminated infections [1]. Gonococcal infections continue to be a cause of major health concern in Western Australia with close to 2000 cases reported in 2012. Disease rate was at 90 per 100000 head of the population. Since 2011, there have been $8 N$. gonorrhoeae infections in blood. Majority of these infections happen in remotest regional aboriginal communities. The infectivity of the organism is such that chance of acquiring infection from a single exposure to an infected sexual partner is $20-30 \%$ for men and even greater for women. Therefore, prompt diagnosis and treatment will eradicate gonococci from infected individuals. Through this case study, I report the case of an un-suspecting patient who presented with fever and was diagnosed with $\mathrm{N}$. gonorrhoeae.

\section{Case Study}

A 41 year old man from one of the remote communities of Western Australia presented to the Emergency department of Kalgoorlie regional hospital complaining of fever. The aetiology was unknown and the patient was a habitual drinker of alcohol.

\section{Preliminary investigations}

As the aetiology of the fever was unknown, the Emergency department physician wrote a series of investigations involving biochemistry, haematology and blood culture. The tests ordered included full blood picture, electrolytes, liver function tests, CRP, alcohol, calcium and magnesium. The blood culture was done on an aerobic and an anaerobic bottle. Both bottles were loaded to BACTEC
9240 machine (Becton Dickinson) and left to incubate for 72 hour period.

\section{Laboratory results}

The results from biochemical and haematology analysers are summarised in Tables 1 and 2. The biochemistry tests were performed on V5600 analyser (Ortho-clinical Diagnostics) and LH500 analyser (Beckman Coulter).

\begin{tabular}{|c|c|c|}
\hline \multicolumn{3}{|l|}{ Electrolytes } \\
\hline Sodium & $133 \mathrm{mmol} / \mathrm{L}$ & $133-146 \mathrm{mmol} / \mathrm{L}$ \\
\hline Potassium & $4.3 \mathrm{mmol} / \mathrm{L}$ & $3.4-5.0 \mathrm{mmol} / \mathrm{L}$ \\
\hline Chloride & $94 \mathrm{mmol} / \mathrm{L}$ & $98-108 \mathrm{mmol} / \mathrm{L}$ \\
\hline Bicarbonate & $24 \mathrm{mmol} / \mathrm{L}$ & $22-32 \mathrm{mmol} / \mathrm{L}$ \\
\hline Anion Gap & $19 \mathrm{mmol} / \mathrm{L}$ & $10-22 \mathrm{mmol} / \mathrm{L}$ \\
\hline Urea & $4.4 \mathrm{mmol} / \mathrm{L}$ & $3.0-8.0 \mathrm{mmol} / \mathrm{L}$ \\
\hline Creatinine & $78 \mathrm{mmol} / \mathrm{L}$ & $60-110 \mathrm{mmol} / \mathrm{L}$ \\
\hline eGFR & $>90 \mathrm{~mL} / \mathrm{min} / 1.73 \mathrm{~m}^{2}$ & $>60 \mathrm{~mL} / \mathrm{min} / 1.73 \mathrm{~m}^{2}$ \\
\hline \multicolumn{3}{|c|}{ Liver Function Tests } \\
\hline Total Protein & $73 \mathrm{~g} / \mathrm{L}$ & $60-80 \mathrm{~g} / \mathrm{L}$ \\
\hline Albumin & $34 \mathrm{~g} / \mathrm{L}$ & $35-50 \mathrm{~g} / \mathrm{L}$ \\
\hline Globulins & $39 \mathrm{~g} / \mathrm{L}$ & $25-44 \mathrm{~g} / \mathrm{L}$ \\
\hline Bilirubin & $22 \mathrm{~g} / \mathrm{L}$ & $<20 \mathrm{~g} / \mathrm{L}$ \\
\hline Alk. Phos & $103 \mathrm{U} / \mathrm{L}$ & $35-135 \mathrm{U} / \mathrm{L}$ \\
\hline ALT & $42 \mathrm{U} / \mathrm{L}$ & $<40 \mathrm{U} / \mathrm{L}$ \\
\hline
\end{tabular}




\begin{tabular}{|c|c|c|}
\hline Gamma GT & $618 \mathrm{U} / \mathrm{L}$ & $<60 \mathrm{U} / \mathrm{L}$ \\
\hline \multicolumn{3}{|c|}{ General Chemistry } \\
\hline Calcium, Total & $1.97 \mathrm{mmol} / \mathrm{L}$ & $(2.15-2.60) \mathrm{mmol} / \mathrm{L}$ \\
\hline Calcium, Corr & $2.09 \mathrm{mmol} / \mathrm{L}$ & $(2.15-2.60) \mathrm{mmol} / \mathrm{L}$ \\
\hline Magnesium & $0.32 \mathrm{mmol} / \mathrm{L}$ & $(0.70-1.10) \mathrm{mmol} / \mathrm{L}$ \\
\hline $\begin{array}{l}\text { C-Reactive } \\
\text { Protein }\end{array}$ & $32 \mathrm{mg} / \mathrm{L}$ & $<10 \mathrm{mg} / \mathrm{L}$ \\
\hline Alcohol & $<0.010 \%$ & \\
\hline
\end{tabular}

Table 1: The results from the blood biochemistry showed abnormal liver function tests with increased ALT and gamma GT results confirming the patient's habitual drinking status. The CRP was also elevated suggesting an acute inflammation.

\begin{tabular}{|l|l|l|}
\hline \multicolumn{2}{|l|}{ Haematology Results } & \multicolumn{2}{|l|}{} \\
\hline RCC & $4.28 \times 10^{12} / \mathrm{L}$ & $(4.50-5.50) \times 10^{12} / \mathrm{L}$ \\
\hline $\mathrm{Hb}$ & $138 \mathrm{~g} / \mathrm{L}$ & $(135-180) \mathrm{g} / \mathrm{L}$ \\
\hline Platelets & $86 \times 10^{9} / \mathrm{L}$ & $(150-400) \times 10^{9} / \mathrm{L}$ \\
\hline WBC & $13.0 \times 10^{9} / \mathrm{L}$ & $(4.00-11.00) \times 10^{9} / \mathrm{L}$ \\
\hline Neutrophils & $84.1 \%$ or $10.9 \times 10^{9} / \mathrm{L}$ & $(2.00-7.50) \times 10^{9} / \mathrm{L}$ \\
\hline Lymphocytes & $3.4 \%$ or $0.44 \times 10^{9} / \mathrm{L}$ & $(1.20-4.00) \times 10^{9} / \mathrm{L}$ \\
\hline Monocytes & $12.3 \%$ or $1.60 \times 10^{9} / \mathrm{L}$ & $(0.20-1.0) \times 10^{9} / \mathrm{L}$ \\
\hline Basophils & $0.2 \%$ or $0.03 \times 10^{9} / \mathrm{L}$ & $(0.00-0.20) \times 10^{9} / \mathrm{L}$ \\
\hline
\end{tabular}

Table 2: The full blood picture results returned a high WBC count with majority of the cells being neutrophils and monocytes, indicating an underlying infectious disease process Table 2.

The blood results prompted the physician to admit the patient to medical ward and commence treatment. The patient was given 3 IV doses of Ceftriaxone and was discharged with a dose of Co-amoxiclav. At the time of discharge from the hospital, the patient had no arthritis and was responding well to treatment.

\section{Microbiology results}

The blood culture machine flagged positive for aerobic bottle on day 3 of the incubation. The bottle was then processed for Gram's stain, culture and sensitivity results. Faint looking Gram-negative diplococci were seen on the smear but not conclusive of Neisseria. The sediment was also cultured to blood agar, macConkey agar, LBAG (Laked blood agar with gentamicin), chocolate agar and GCLECT medium. On day 4, tiny, glistening, 1-2 mm white colonies were seen growing in chocolate agar Figure 1, blood agar Figure 2 and GCLECT medium Figure 3. No growth was seen in macConkey agar. The colonies were Gram stained and showed Gram-negative diplococcic Figures 4 and 5 . The colonies were super-oxol positive and oxidase positive. Beta lactamase test was negative. The preliminary findings were conveyed to the treating physician. The physician was advised by the clinical microbiologist to re-call the patient, do STI Screen, start Azithromycin treatment and finish the course with Amoxycillin $1 \mathrm{~g}$ tds, total $7 / 7$ antibiotics.

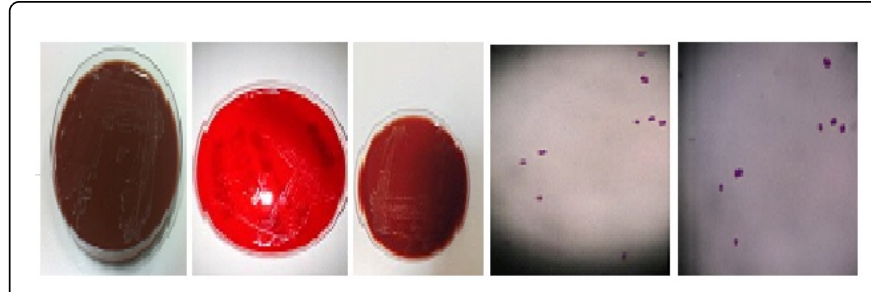

Figure 1: N.Gonorrhoeae growing on chocoloate agar; Figure 2: Growth on blood agar; Figure 3: Growth on GC LECT agar; Figures 4 and 5: Gram stain results

Being a small regional laboratory, Kalgoorlie laboratory had very limited expertise in confirming and identifying Neisseria gonorrhoeae from blood culture. Therefore, the culture plates and the blood culture bottle were sent to the reference laboratory in QEII Medical centre, Perth. The reference laboratory performed MALDI-TOF assay (Matrix-Assisted Laser Desorption Ionisation -Time of Flight) that confirmed the organism to be Neisseria gonorrhoeae. The organism was also confirmed using VITEK 2 testing system with a result of 99.9\% probability. The VITEK test returned an ID of M5555; Bio Number 5237000000.

MIC testing was done on the isolate and it was found to be sensitive to Penicillin $(\mathrm{MIC}=0.25 \mathrm{~g} / \mathrm{L})$, Ceftriaxone $(\mathrm{MIC}=0.008 \mathrm{mg} / \mathrm{L})$ and Ciprofloxacin (MIC=0.004 mg/L).

Being a notifiable disease, the reference laboratory immediately notified the Department of Health, Government of Western Australia with the result. The physicians at Kalgoorlie hospital were also contacted, who in turn contacted the patient and started IV antibiotic treatment.

\section{Discussion}

Neisseria gonorrhoeae generally causes genital, pharyngeal and ano-rectal infections. Disseminated infections are very rare and this case study was an ideal example. Earlier studies have shown that disseminated infections are often preceded by asymptomatic mucosal infections [1]. In this case study, intermittent fever with high white cell count and CRP suggested a stage of acute inflammation. Predisposing risk factors like homosexuality or bisexuality may also be a cause but in this instance, no details were mentioned in patient history. Though there may be various hypotheses as to how the disseminated infection might have occurred, it was speculated that asymptomatic gonococcal pharyngitis preceded dissemination and that ruptured vessels on the oesophageal mucosa was the likely route of dissemination. Gonococcal bacteraemia is often intermittent and not all patients give a positive blood culture. However if three consecutive sets of blood cultures collected at the same time give a positive result, then bacteraemia should be suspected $[2,3]$. The organism isolated in this case study was Pencillin sensitive and also sensitive to Ceftriaxone and Ciprofloxacin. The organism was identified by chance and had it not been for the blood culture, perhaps, it would not have been identified. Prompt identification and empirical treatment of the patient helped in preventing the spread of the disease to other parts of the body. 
Page 3 of 3

\section{Acknowledgement}

I express my thanks to Mr. Joseph Kim, Medical scientist at Path West Laboratory, Kalgoorlie branch for assisting me in collating the data needed for preparing this article.

\section{References}

1. Won D, An D, Kim M, Sang Lee Y (2011) A Case of Bacteraemia by Neisseria gonorrhoeae Coincident with Massive Haemorrhage of Oesophageal Varices. Korean J Lab Med 31:118-121
2. Marazzo JM (2005) Neisseriae gonorrhoeae. In: Mandell GL, Bennett JE, et al.eds. Principles and practice of infectious diseases. 7th ed.Philadelphia:Lippincott Williams \& Wilkins: 2762-5.

3. PathWest Laboratory Medicine database. 